\title{
Poly(ethylene oxide) Macromonomers IX. Synthesis and Polymerization of Macromonomers Carrying Styryl End Groups with Enhanced Hydrophobicity
}

\author{
Dongri Chao, Shinichi Itsuno, and Koichi Ito* \\ Department of Materials Science, Toyohashi University of Technology, \\ Tempaku-cho, Toyohashi 441, Japan
}

(Received February 1, 1991)

\begin{abstract}
Poly(ethylene oxide) (PEO) macromonomers with hydrophobically enhanced styryl end groups were prepared by three methods. The first consists of polymerization of ethylene oxide (EO) with potassium alkoxide of mono( $t$-butyldimethylsilyl)ether of 1,10-decanediol, termination with methyl iodide, desilylation with tetra- $n$-butylammonium fluoride, followed by coupling with $p$-vinylbenzyl chloride to afford a $p$-vinylbenzyloxydecyloxy-ended macromonomer. The second is a simpler method, consisting of polymerization of EO with a simpler potassium alkoxide and termination with $p$-styrylalkyl bromide to afford a $p$-styrylalkyloxy-ended macromonomer, but the termination was accompanied with a rather abundant side reaction due to E2 elimination to yield $p$-styrylalkene and hydroxy-ended PEO. This shortcoming could be overcome by the third method of transforming the hydroxy end group by reacting with about five-fold molar excess of sodium hydride and $p$-styrylalkyl bromide, except for $p$-styrylethyl bromide which exclusively reacted by $\mathrm{E} 2$ elimination to give $p$-divinylbenzene. The radical homopolymerizations of the macromonomers obtained were found to be very rapid in water, particularly for those with more hydrophobic styryl end groups, supporting our previous idea of the organized micellar polymerization mechanism for these amphiphilic PEO macromonomers.
\end{abstract}

KEY WORDS Poly(ethylene oxide) / Macromonomer / Amphiphilic Monomer / p-Styrylalkyl End Group / Micellar Polymerization /

Poly(ethylene oxide) has been one of the well-known water-soluble nonionic polymers with a variety of practical applications. ${ }^{1}$ PEO macromonomers have also been a subject of many recent publications to prepare ${ }_{\mathrm{f}^{\prime}}$ welldefined amphiphilic graft copolymers by copolymerizing with any hydrophobic comonomers. ${ }^{2-7}$ We have prepared a series of amphiphilic macromonomers, $\mathbf{1}$ and $\mathbf{2}$, with their hydrophilic-hydrophobic balance being controlled by the terminal alkyloxy group and/or the PEO chain length. ${ }^{7-9}$

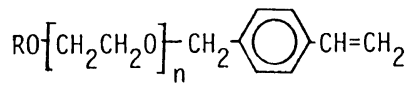

1 (R-PEO-VB-n)

\footnotetext{
* To whom correspondence should be addressed.
}

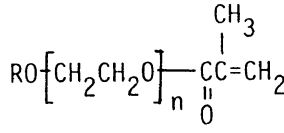

$$
2 \text { (R-PEO-MA-n) }
$$

The radical homo- and copolymerizations have been studied in detail to show the importance of their structure and solution property in determining their apparent polymerizability. Recent particular interest has been paid to their specific polymerization behavior in water resulting from their amphiphilic property. ${ }^{8,9}$ Thus the polymerizations of 1 or 2 were found to occur unusually rapidly in water to give regular comb- or star-like polymers. Organization of their hydrophobic $\alpha$ terminal double bonds into the micelle core 
was considered as a key factor for the enhanced polymerization. The significant effects of the $\omega$-alkoxy groups and the PEO chain lengths were observed, indicating the importance of their relative molecular density or arrangement in the micelles, as supported by the light scattering measurements of micellization of their nonpolymerizable macromonomer models. In general, the macromonomers with higher molecular density, as estimated by $m / V_{\mathrm{m}}$, where $m$ and $V_{\mathrm{m}}$ are the average number of aggregation and the volume of each micelle, respectively, was found to polymerize more rapidly.

The above observation prompted us to prepare PEO macromonomers carrying terminal double bonds with enhanced hydrophobicity which will make their micelles organize even more preferably for polymerization. They are also expected to be promising as useful dispersant comonomers for soap-free dispersion polymerizations of water-insoluble monomers. $^{4,6,7}$ This paper is intended to present and discuss three methods of preparation of such PEO macromonomers with styryl end groups, $\mathbf{3}$ and 4, according to Schemes 1, 2 , and 3 , which will be named in the following as the initiation, the termination, and the transformation methods, respectively, because the hydrophobic functions are introduced during the corresponding steps. The last two methods to prepare $\mathbf{4}$ are clearly simpler in that the polymerizable styryl end groups are introduced together with the hydrophobic functions at the same time.

$$
\begin{aligned}
& \mathrm{CH}_{3} O\left\{\mathrm{CH}_{2} \mathrm{CH}_{2} \mathrm{O}\right]_{\mathrm{n}}\left(\mathrm{CH}_{2} \mathrm{t}_{10} \mathrm{OCH}_{2} \bigcirc \mathrm{CH}=\mathrm{CH}_{2}\right. \\
& 3\left(C_{1}-P E O-C_{10}-V B-n\right) \\
& \mathrm{RO}\left\{\mathrm{CH}_{2} \mathrm{CH}_{2} \mathrm{O}\right]_{\mathrm{n}}\left(\mathrm{CH}_{2}\right)_{\mathrm{m}} \bigcirc \mathrm{CH}=\mathrm{CH}_{2} \\
& 4\left(R-P E O-C_{m}-S-n\right)
\end{aligned}
$$

\section{EXPERIMENTAL}

\section{Materials}

1,10-Decanediol from Tokyo Kasei Kogyo Co., Ltd. was recrystallized from hexane, and reacted with $t$-butyldimethylsilyl chloride from Shinetsu Chem. Co., Ltd. to afford the mono( $t$-butyldimethylsilyl)ether, according to the procedure of McDougal et al. ${ }^{10}$ Methyl iodide was distilled over calcium hydride under vacuum into an ampoule with a breakable seal. p-2-Bromoethylstyrene was prepared from 2bromoethylbenzene by acetylation, followed by reduction with sodium borohydride and dehydration, in a similar manner as reported. ${ }^{11}$ $p$-(4-Bromobutyl)styrene and $p$-(7-bromoheptyl)styrene were prepared by reactions of $p$-vinylbenzylmagnesium chloride with 1,3dibromopropane and 1,6-dibromohexane, respectively according to the procedure of Tomoi and coworkers. ${ }^{12}$ All the other reagents and solvents were prepared and/or purified according to the procedures previously described. ${ }^{7-9}$ Poly(ethylene glycol) monomethyl ether and mono- $t$-butyl ether, 10 with $\mathrm{R}=\mathrm{CH}_{3}$ and $t-\mathrm{C}_{4} \mathrm{H}_{9}$, were prepared by polymerization of EO with potassium 2-methoxyethoxide and $t$-butoxide, similarly as before. ${ }^{7,8}$

\section{Preparation of Macromonomers}

Polymerization of EO was carried out in tetrahydrofuran (THF) at $40^{\circ} \mathrm{C}$ under vacuum, and terminated or end-capped with appropriate coupling reagents, using a conventional breakable seal technique. ${ }^{7}$ Preparation according to Scheme 1 was conducted as follows. Mono( $t$-butyldimethylsilyl)ether of 1,10-decanediol was titrated in THF with a THF solution of potassium naphthalene until the color of the latter did not disappear, to afford the alkoxide, 5. The resulting jelly-like solution was used to polymerize $\mathrm{EO}$ at $40^{\circ} \mathrm{C}$ for $24 \mathrm{~h}$ to give a relatively clear solution, which was terminated with methyl iodide to afford 6. Desilylation with tetra- $n$-butylammonium fluoride and the isolation of the hydroxy derivative, 7 , was 


$$
\begin{aligned}
& \left.\mathrm{tBuME}_{2} \mathrm{SiO}\left(\mathrm{CH}_{2}\right)_{10} \mathrm{OK} \stackrel{\mathrm{EO}}{=} \stackrel{\mathrm{MeI}}{\longrightarrow} \mathrm{tBuMe}_{2} \mathrm{SiO}\left(\mathrm{CH}_{2}\right)_{10} 0 \mathrm{FCH}_{2} \mathrm{CH}_{2} \mathrm{O}\right]_{\mathrm{n}}-\mathrm{CH}_{3} \stackrel{\text { TBAF }}{\longrightarrow} \\
& 5 \\
& 6 \\
& \mathrm{HO}\left(\mathrm{CH}_{2}\right)_{10} \mathrm{O}\left[\mathrm{CH}_{2} \mathrm{CH}_{2} \mathrm{O}\right]_{\mathrm{n}} \mathrm{CH}_{3} \stackrel{\mathrm{NaH}+\mathrm{VBC}}{\longrightarrow} \mathrm{CH}_{2}=\mathrm{CH} \bigcirc \mathrm{CH}_{2} \mathrm{O}\left(\mathrm{CH}_{2}\right)_{10} \mathrm{O} \mathrm{FCH}_{2} \mathrm{CH}_{2} \mathrm{O} \mathrm{T}_{\mathrm{n}} \mathrm{CH}_{3} \\
& 7
\end{aligned}
$$

Scheme 1 .

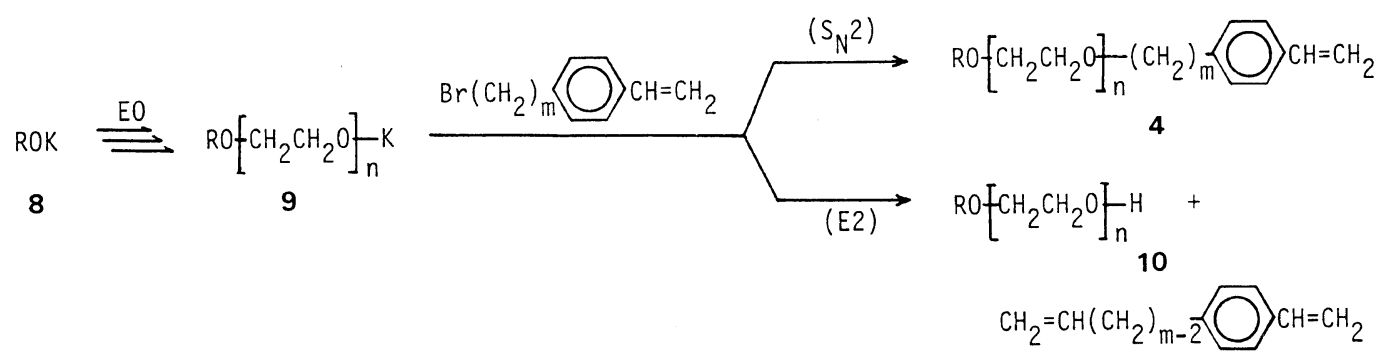

Scheme 2.

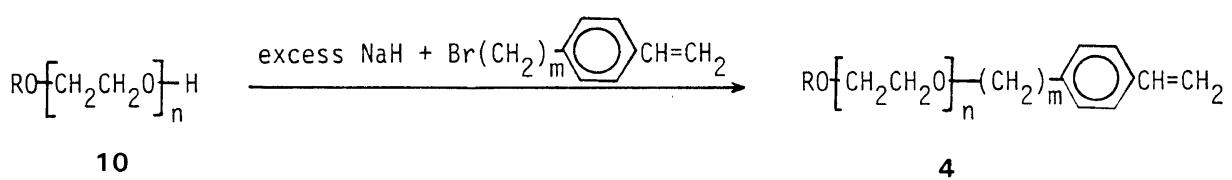

Scheme 3.

performed as before. ${ }^{9} 7$ was reacted with five-fold molar excess of sodium hydride and $p$-vinylbenzyl chloride (VBC) at $30^{\circ} \mathrm{C}$ for $1 \mathrm{~h}$. The reaction mixture was poured into acetone to precipitate sodium chloride, which was filtered off. The filtrate was evaporated under a reduced pressure to almost dryness and poured into hexane. The polymers precipitated were collected, washed repeatedly with hexane, and freeze-dried from benzene.

The termination method according to Scheme 2 was conducted by the same procedure as previously described for preparation of $1 .^{7,8}$ The polymers were isolated similarly as described above. The polymer yields were almost quantitative after polymerization for $24 \mathrm{~h}$ at $40^{\circ} \mathrm{C}$. The transformation method (scheme 3) was conducted under nitrogen by reacting the hydroxy-ended $\mathrm{PEO}$ with five-fold excess of sodium hydride and $p$-bromoalkyl- styrenes. The polymers were almost quantitatively isolated and purified as above.

Model Reactions between Potassium Alkoxides and p-7-Bromoheptylstyrene

In order to examine rather abundant side reactions (E2) in the termination method (Scheme 2), some model reactions were conducted with potassium ethoxide, $n$-butoxide, and 2-methoxyethoxide in place of PEO alkoxides, 9. Potassium alkoxides were used in five- to eight-fold molar excess of $p$-(7bromoheptyl)styrene (BHS) in order to simplify the product analysis. The reaction mixtures were evaporated to remove the solvents and analyzed by ${ }^{1} \mathrm{H}$ NMR to estimate the composition of the corresponding alkyl $p$-styrylheptyl ether $\left(S_{\mathrm{N}} 2\right)$ and $p$-6-heptenylstyrene (E2). The conversion of BHS was found in each case to be almost quantitative. 
Polymerization of Macromonomers

Radical homopolymerizations of the macromonomers, 4, were carried out at $60^{\circ} \mathrm{C}$ either in water $\left(\mathrm{D}_{2} \mathrm{O}\right)$ with $4,4^{\prime}$-azobis(4-cyanovaleric acid) (AVA) or in benzene $\left(\mathrm{C}_{6} \mathrm{D}_{6}\right)$ with 2,2'-azobisisobutyronitrile (AIBN), as previously described. ${ }^{8}$ The corresponding monomer, solvent, and initiator were sealed in an NMR tube under argon after being freed from air either by freeze-thaw cycles in the case of polymerization in benzene or by bubbling argon gas for about five minutes in the case of polymerization in water. Conversions were monitored by means of ${ }^{1} \mathrm{H}$ NMR following the disappearance of the styryl double bond peaks in reference to the oxyethylene peaks. The polymerization system was apparently clear (transparent) throughout.

\section{Methods of Characterization}

${ }^{1} \mathrm{H}$ NMR $(270 \mathrm{MHz})$, gel permeation chromatography (GPC), and vapor pressure osmometry (VPO) were measured as previously described. ${ }^{7,8}$

\section{RESULTS AND DISCUSSION \\ Preparation of a Macromonomer by Initiation Method (Scheme 1) \\ The results are given in Table I and Figure 1, which show that the expected macro-}

monomer, $\mathrm{C}_{1}-\mathrm{PEO}-\mathrm{C}_{10}-\mathrm{VB}, \mathbf{3}$, was obtained with satisfactory end functionality, $f$, but that the average degree of polymerization, $n$, was much higher than that expected from the feed molar ratio of the monomer to the initiator and the molecular weight distribution, $M_{w} / M_{n}$, estimated by GPC, was rather broad, probably because of a poor initiation efficiency of the initiator, 5, which appeared a gel-like solid in THF. Also unfortunately, the macromonomer, 3, obtained was scarcely soluble in water to apply for a micellar polymerization. So we proceeded to a much simpler termination method as follows.

\section{Preparations of Macromonomers by Termina- tion Method (Scheme 2)}

Since simple potassium alkoxides are well known to initiate the living polymerization of

Table I. Preparation of $\mathrm{C}_{1}-\mathrm{PEO}-\mathrm{C}_{10}-\mathrm{VB}, 3$, according to Scheme 1

\begin{tabular}{|c|c|c|c|c|c|c|}
\hline \multirow{2}{*}{$\frac{[\mathrm{EO}]_{0}}{\mathrm{mmol}}$} & \multirow{2}{*}{$\frac{[5]_{0}}{\mathrm{mmol}}$} & \multirow{2}{*}{$\frac{[\mathrm{EO}]_{0}}{[5]_{0}}$} & \multirow{2}{*}{$\begin{array}{c}\begin{array}{c}\text { Polymer } \\
\text { yield }\end{array} \\
\%\end{array}$} & \multicolumn{2}{|c|}{$n$} & \multirow{2}{*}{$\frac{M_{w} / M_{n}}{\mathrm{GPC}^{\mathrm{b}}}$} \\
\hline & & & & $\mathrm{NMR}^{\mathrm{a}}$ & VPO & \\
\hline 195 & 3.5 & 56 & 47 & 132 & 122 & 1.19 \\
\hline 115 & 3.5 & 33 & 55 & 120 & - & 1.17 \\
\hline
\end{tabular}

a From the ratio of the peak areas of oxyethylene to vinyl proteins.

b Calibrated with PEO standard samples.

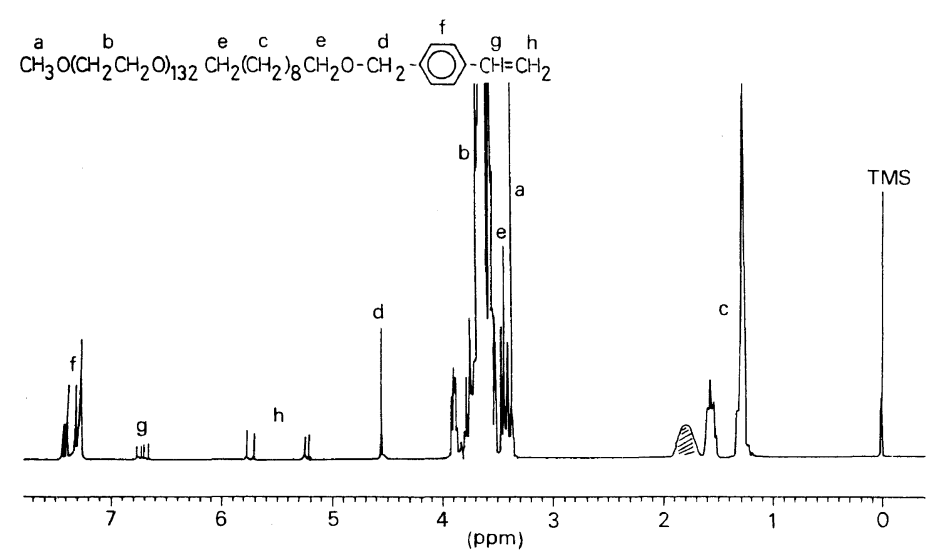

Figure 1. ${ }^{1} \mathrm{H}$ NMR spectrum of $\mathrm{C}_{1}-\mathrm{PEO}-\mathrm{C}_{10}-\mathrm{VB}-132$ in $\mathrm{CDCl}_{3}$ (a hatched peak due to water). 
EO with a reasonable rate and a good end-functionality, ${ }^{1,2,7-9}$ we first expected the termination with $p$-bromoalkylstyrenes to afford the desired macromonomers, 4, as shown in Scheme 2. Thus potassium 2methoxyethoxide was used to polymerize EO, followed by termination with $p$-(2-bromoethyl)styrene (BES) and $p$-(7-bromoheptyl)styrene (BHS) with the results given in Table II, together with those of termination with VBC. It was found that VBC was successful as before ${ }^{7,8}$ to afford the macromonomer, $\mathrm{C}_{1}-\mathrm{PEO}-\mathrm{VB}, \mathrm{I}$ with $\mathrm{R}=\mathrm{CH}_{3}$, while the other terminating reagents suffered from a rather abundant elimination reaction (E2) to yield $p$ - $\omega$-alkenylstyrenes and hydroxy-ended PEO, $\mathbf{1 0}$, instead of the desired substitution reaction $\left(S_{\mathrm{N}} 2\right)$.

The apparent end-functionality, $f$ in Table II, means the fraction of the expected styryl end groups among the total PEO polymers recovered by precipitation into hexane. Since the supernatant solution was found by ${ }^{1} \mathrm{H}$ NMR, after evaporation, to include the $p$ $\omega$-alkenylstyrene in a reasonable proportion to the excess $p$ - $\omega$-bromoalkylstyrene, $f$ can also be taken as the fraction of the $S_{\mathrm{N}} 2$ reaction and $1-f$ as that of the E2. The fact that $f=0$ for BES indicates the exclusive $\mathrm{E} 2$ reaction, probably because of the extensive resonance stabilization of the product, $p$-divinylbenzene. Even a higher derivative, BHS, gave the expected $S_{\mathrm{N}} 2$ product in only about $30 \%$ yield, so that the PEO potassium alkoxide appeared to be highly basic to abstract the $\beta$-hydrogens of the alkyl bromide by the E2 mechanism rather than to attack on the $\alpha$-carbon by the $S_{\mathrm{N}} 2$ mechanism. It was considered to be of value to examine the effects of the reaction conditions in comparison with those of the model reactions using simpler alkoxides of low molecular weights.

Table III shows that the reaction of PEO potassium alkoxide with BHS becomes more favorable for the $S_{\mathrm{N}} 2$ mechanism at higher temperature and in THF than in benene. In
Table II. Termination of $\mathrm{CH}_{3} \mathrm{O} \mathrm{CCH}_{2} \mathrm{CH}_{2} \mathrm{O}_{{ }_{n}} \mathrm{~K}$ with $p$-halostyrenes ${ }^{a}$

\begin{tabular}{lcc}
\hline \multicolumn{1}{c}{ Terminating reagent } & \multicolumn{1}{c}{$n$} & $\begin{array}{c}\text { Double bond } \\
\text { end-functionality }\end{array}$ \\
& $\mathrm{GPC}^{\mathrm{c}}, f$
\end{tabular}

a Reactions were carried out with five-fold molar excess of the terminating reagents at $30^{\circ} \mathrm{C}$ for $2 \mathrm{~h}$ in tetrahydrofuran (THF).

b Calibrated with PEO standard samples.

c Calculated from the ratio of the peak areas of vinyl to oxyethylene protons, based on the $n$ determined by GPC.

Table III. Termination of $\mathrm{CH}_{3} \mathrm{O}\left[\mathrm{CH}_{2} \mathrm{CH}_{2} \mathrm{O}_{n} \mathrm{~K}\right.$ $(n=38)$ with $p$-(7-bromohepthyl)styrene (BHS) ${ }^{\mathrm{a}}$

\begin{tabular}{|c|c|c|c|}
\hline \multirow[t]{2}{*}{ Solvent } & \multirow{2}{*}{$\frac{\text { Temp }}{{ }^{\circ} \mathrm{C}}$} & \multirow{2}{*}{$\begin{array}{c}\begin{array}{c}\text { Reaction } \\
\text { time }\end{array} \\
\mathrm{h}\end{array}$} & \multirow{2}{*}{$\begin{array}{l}\text { Double bond } \\
\text { end-function- } \\
\text { ality, } f \% \\
\left(\text { or } S_{\mathrm{N}} 2 \% \text { ) }\right.\end{array}$} \\
\hline & & & \\
\hline THF & 0 & 24 & 8 \\
\hline THF & 30 & 1 & 32 \\
\hline THF & 60 & 0.5 & 50 \\
\hline Benzene & 30 & 2 & 16 \\
\hline Benzene & 60 & 0.5 & 30 \\
\hline
\end{tabular}

${ }^{\mathrm{a}}[\mathrm{BHS}] /[\mathrm{PEO}-\mathrm{K}]=5-8,[\mathrm{PEO}-\mathrm{K}]=20 \mathrm{mmol}^{-1}$.

contrast, Table IV shows that the simpler alkoxides undergo the $S_{\mathrm{N}} 2$ reaction more faborably in benzene than in THF, and the effect of temperature appears to be not so much significant. Moreover, the $S_{\mathrm{N}} 2$ reaction is generally much more favored than the E2 reaction, particularly for the simplest alkoxides without ether oxygens, and indeed becomes almost quantitative, to be of synthetic value, in the corresponding alcohol as the solvent.

These results suggest that the ether oxygens in PEO strongly solvate the potassium ions to cause their terminal alkoxides highly basic, particularly in a nonpolar solvent, to favor the E2 reaction route. Successful $S_{\mathrm{N}} 2$ reactions as found in the alcoholic solvents may well result 
Table IV. Model reactions of potassium alkoxides with $p$-(7-bromoheptyl)styrene (BHS) ${ }^{\mathbf{a}}$

\begin{tabular}{|c|c|c|c|c|c|}
\hline \multirow{2}{*}{ ROK } & \multirow{2}{*}{ Solvent } & \multirow{2}{*}{$\frac{\text { Temp }}{{ }^{\circ} \mathrm{C}}$} & \multirow{2}{*}{$\frac{\text { Time }}{\mathrm{h}}$} & \multirow{2}{*}{$S_{\mathrm{N}} 2 \%$} & \multirow{2}{*}{ E2 \% } \\
\hline & & & & & \\
\hline \multirow[t]{5}{*}{$\mathrm{CH}_{3} \mathrm{OCH}_{2} \mathrm{CH}_{2} \mathrm{OK}$} & THF & 30 & 2 & 30 & 70 \\
\hline & Benzene & 30 & 2 & 58 & 42 \\
\hline & Benzene & 60 & 0.5 & 75 & 25 \\
\hline & Benzene & 80 & 0.3 & 62 & 38 \\
\hline & $\mathrm{CH}_{3} \mathrm{OCH}_{2} \mathrm{CH}_{2} \mathrm{OH}$ & 30 & 2 & 95 & 5 \\
\hline \multirow[t]{2}{*}{$\mathrm{CH}_{3} \mathrm{CH}_{2} \mathrm{OK}$} & Benzene & 30 & 12 & 87 & 13 \\
\hline & Ethanol & 30 & 2 & 100 & 0 \\
\hline$n-\mathrm{C}_{4} \mathrm{H}_{9} \mathrm{OK}$ & Benzene & 30 & 12 & 88 & 12 \\
\hline
\end{tabular}

${ }^{\mathrm{a}}[\mathrm{ROK}] /[\mathrm{BHS}]=5-8,[\mathrm{BHS}]=20 \mathrm{mmoll}^{-1}$.

from a reduced basicity of the alkoxides due to extensive hydrogen bondings. Unfortunately, however, this cannot be usefully applied to the macromonomer synthesis because the corresponding PEO alcohol must be separated from the resulted PEO macromonomer by a cumbersome or time-consuming procedure such as a column chromatography, though this separation was found to be successful, even in very low yield, using a column of silica gel, Wako Gel C-200, with methanol as an eluent. The other attempts to enhance the $S_{\mathrm{N}} 2$ selectivity by reducing the basicity of the PEO alkoxides were tried by conducting the reactions in the presence of various lithium or sodium halides, but resulted in too slow reactions to applicable.

\section{Preparation of Macromonomers by Transfor- mation Methods (Scheme 3)}

From the above results, it was concluded that the termination of the PEO living alkoxides with $p$ - $\omega$-bromoalkylstyrenes (BAS) involved not only the expected $S_{\mathrm{N}} 2$ reaction to afford the macromonomer but also the rather abundant E2 reaction to yeild the corresponding hydroxy-ended PEO. If we cannot avoid the $\mathrm{E} 2$ reaction in nature, then we considered better to transform the side product, the hydroxy-ended PEO, 10, to the expected pure macromonomer, $\mathbf{4}$, by infinitely repeating the conversion to the alkoxide and the subsequent reaction with BAS. This can be accomplished in a single batch by reacting $\mathbf{1 0}$ with sufficient excess of sodium hydride and BAS. In principle, $1 / f$ times molar excess of the reagents is required to transform all hydroxyl groups, if the fraction, $1-f$, of the alkoxide reacts each time by the E2 mechanism to reproduce the alcohol. Then, the overall hydroxyl concentrations to be converted to the alkoxides should be

$$
\begin{aligned}
& {[\mathrm{OH}]_{0}\left[1+(1-f)+(1-f)^{2}+(1-f)^{3}+\cdots\right]} \\
& \quad=[\mathrm{OH}]_{0} / f
\end{aligned}
$$

where $[\mathrm{OH}]_{0}$ is the initial concentration of the hydroxyl end groups.

In practice, five-fold molar excess of sodium hydride and BAS were found satisfactory to obtain the essentially pure macromonomers, as given in Table V. The ${ }^{1} \mathrm{H}$ NMR spectra in Figure 2 clearly proved the expected structures in that both the $\alpha$ - and $\omega$-terminal groups gave rise to the corresponding peaks with satisfactory intensities in reference to those of the oxyethylene units. With this result, we can conclude that a desired PEO macromonomer carrying a $p$-styrylalkyl end group, except for $p$-styrylethyl, can be obtained by reacting a living PEO alkoxide with a sufficient excess of the corresponding $p$-bromoalkylstyrene in the presence of similarly excess of sodium hydride, that is, by a combination of the termination 
Table V. Characterization of macromonomers, $\mathbf{4}$, prepared by transformation method (Scheme 3$)^{\mathrm{a}}$

\begin{tabular}{ccccc}
\hline $\begin{array}{c}\text { Macromonomer } \\
\text { code }\end{array}$ & \multicolumn{2}{c}{$n$} & & $M_{w} / M_{n}$ \\
\cline { 2 - 4 } & $\mathrm{NMR}^{\mathrm{b}}$ & $\mathrm{GPC}^{\mathrm{c}}$ & & $\mathrm{GPC}^{\mathrm{c}}$ \\
& & & & \\
\hline $\mathrm{C}_{1}-\mathrm{PEO}-\mathrm{C}_{4}-\mathrm{S}-29$ & 29.0 & 29.1 & 0.99 & 1.04 \\
$\mathrm{C}_{1}-\mathrm{PEO} \mathrm{C}_{7}-\mathrm{S}-29$ & 29.1 & 29.1 & 0.99 & 1.04 \\
$\mathrm{tC}_{4}-\mathrm{PEO} \mathrm{C}_{4}-\mathrm{S}-35$ & 36.1 & 34.9 & 1.03 & 1.03 \\
$\mathrm{tC}_{4}-\mathrm{PEO} \mathrm{C}_{7}-\mathrm{S}-35$ & 37.6 & 34.5 & 0.96 & 1.03 \\
\hline
\end{tabular}

a Reactions were carried out using the corresponding PEO alcohol with five-fold molar excess of $\mathrm{NaH}$ and the corresponding $p$-bromoalkylstyrene in THF at $30^{\circ} \mathrm{C}$ for 2 days.

b From the ratio of the peak areas of oxyethylene to vinyl protons.

c Calibrated with PEO standard samples.

${ }^{d}$ From the ratio of the peak areas of vinyl to $\omega$ - $t$-butoxy or methoxy protons.

e See 4 for the code representation. $\mathrm{C}_{1}$ and $\mathrm{tC}_{4}$ stand for $\omega$-methoxy and $t$-butoxy groups, respectively. The last figure for $n$ was taken as that determined by GPC.
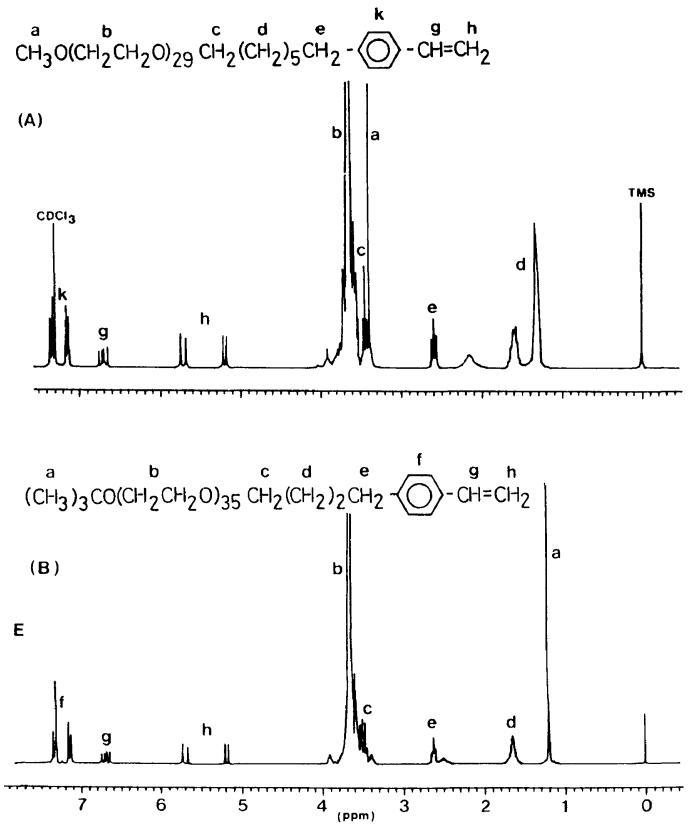

Figure 2. ${ }^{1} \mathrm{H} N M R$ spectra of $(\mathrm{A}) \mathrm{C}_{1}-\mathrm{PEO}-\mathrm{C}_{7}-\mathrm{S}-39$ and (B) $\mathrm{tC}_{4}-\mathrm{PEO}-\mathrm{C}_{4}-\mathrm{S}-35$ in $\mathrm{CDCl}_{4}$.

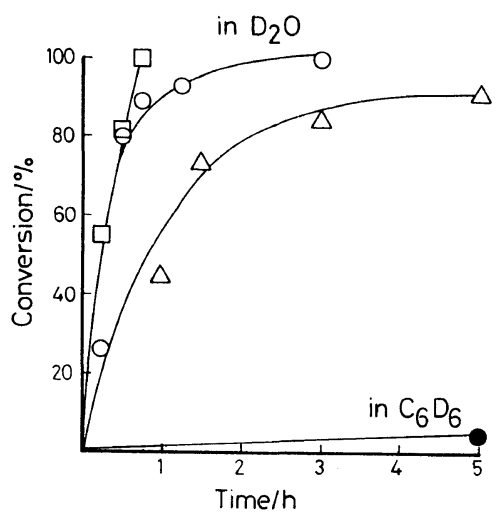

Figure 3. Conversion vs. time plots for polymerization of $\mathrm{C}_{1}-\mathrm{PEO}-\mathrm{C}_{7}-\mathrm{S}-38(\square), \mathrm{C}_{1}-\mathrm{PEO}-\mathrm{C}_{4}-\mathrm{S}-29(\mathrm{O})$, and $\mathrm{C}_{1}-\mathrm{PEO}-\mathrm{VB}-25(\triangle)$ in water with $[\mathrm{M}]=45 \mathrm{mmoll}^{-1}$ and $[\mathrm{AVA}]=0.45 \mathrm{mmoll}^{-1}$. Soild symbol refers to polymerization of $\mathrm{C}_{1}-\mathrm{PEO}-\mathrm{C}_{4}-\mathrm{S}-29$ in benzene with $[\mathrm{M}]=45 \mathrm{mmoll}^{-1}$ and $[\mathrm{AIBN}]=2.25 \mathrm{mmoll}^{-1}$.

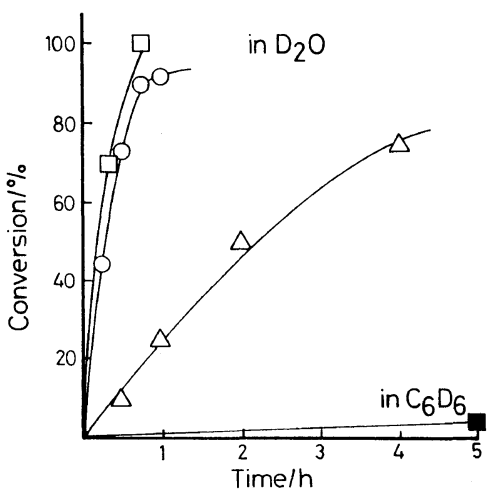

Figure 4. Conversion vs. time plots for polymerization of $\mathrm{tC}_{4}-\mathrm{PEO}-\mathrm{C}_{7}-\mathrm{S}-35(\square), \mathrm{tC}_{4}-\mathrm{PEO}-\mathrm{C}_{4}-\mathrm{S}-35(\mathrm{O})$, and $\mathrm{tC}_{4}-\mathrm{PEO}-\mathrm{VB}-32(\triangle)$ in water with $[\mathrm{M}]=45 \mathrm{mmoll}^{-1}$ and $[\mathrm{AVA}]=0.45 \mathrm{mmoll}^{-1}$. Solid symbol referes to polymerization of $\mathrm{tC}_{4}-\mathrm{PEO}-\mathrm{C}_{7}-\mathrm{S}-35$ in benzene with $[\mathrm{M}]=45 \mathrm{mmoll}^{-1}$ and $[\mathrm{AIBN}]=2.25 \mathrm{mmoll}^{-1}$.

and the transformation methods.

\section{Radical Homopolymerization of the Macro- monomers}

Figures 3 and 4 show the results of time-conversion plots for the polymerizations of the macromonomers, given in Table $\mathrm{V}$, in comparison with those of the previously reported, $p$-vinylbenzyl-ended macromonomers of comparable chain lengths. ${ }^{8}$ As previously 
observed, the polymerizations were also unusually rapid in water as compared to those in benzene. More interestingly here, the present macromonomers with $p$-styrylalkyl (butyl or heptyl) end groups in water polymerized even more rapidly than those with $p$-vinylbenzyl (or $p$-styrylmethyl) groups. This result clearly supports our previous idea of micellar organized polymerization, because the styryl end groups with increased hydrophobicity are reasonably expected to organize more compactly into the micelle cores to enhance their polymerization.

Since the decomposition rates of AVA in water and AIBN in benzene were found to be only a little different from each other, ${ }^{8}$ and also in the presence of poly(ethylene glycol) (MW 1000), ${ }^{13}$ we believe that the enhanced micellular polymerization is a result of decrease in the termination rate $\left(k_{\mathrm{t}}\right)$ and/or increase in the propagation rate $\left(k_{\mathrm{p}}\right)$ but not a result of increase in the initiation rate.

\section{CONCLUSION}

PEO macromonomers with $p$-styrylalkyl end groups could be prepared by the transformation method or in combination with the termination method. The radical homopolymerization in water was very fast as expected for a micellar organized polymerization. These macromonomers are expected to be also promising for applications to dispersion polymerization or to anionic polymerization. Details including the micellar polymerization will be published in due course.

Acknowledgements. The authors are indebted to Shinetsu Chem. Co., Ltd. for $t$-butyldimethylsilyl chloride and to Seimi Chem. Co., Ltd. for $p$-vinylbenzyl chloride. This work was supported in part by a
Grant-in-Aid for General Scientific Research (No. 01470111), from the Ministry of Education, Science, and Culture of Japan.

\section{REFERENCES}

1. (a) M. J. Schick, Ed., "Nonionic Surfactants: Physical Chemistry," Marcel Dekker, New York, N.Y., 1987; (b) F. E. Bailey, Jr. and J. V. Koleske, "Alkylene Oxide and Their Polymers," Marcel Dekker, New York, N. Y., 1990.

2. (a) P. Masson, G. Beinert, E. Franta, and P. Rempp, Polym. Bull., 7, 17 (1982); (b) P. Rempp, P. Lutz, P. Masson, P. Chaumont, and E. Franta, Makromol. Chem., Suppl., 13, 47 (1985).

3. Y. Gnanou and P. Rempp, Makromol. Chem., 188, 2111 (1987).

4. M. Akashi, D. Chao, E. Yashima, and N. Miyauchi, J. Appl. Polym. Sci., 39, 2027 (1990).

5. (a) T. Hamaide, A. Revillon, and A. Guyot, Eur. Polym. J., 20, 855 (1984); (b) T. Hamaide, A. Revillon, and A. Guyot, Eur. Polym. J., 23, 787 (1987).

6. F. Hoshino, M. Sakai, and H. Kawaguchi, Polym. J., 20, 855 (1987).

7. (a) K. Ito, H. Tsuchida, T. Kitano, E. Yamada, and T. Matsumoto, Polym. J., 17, 827 (1985); (b) S. Itsuno, K. Yamazaki, F. Arakawa, T. Kitano, K. Ito, E. Yamada, and T. Matsumoto, Kobunshi Ronbunshu, 43, 91 (1986); (c) K. Ito, T. Tsuchida, T. Kitano, Polym. Bull., 15, 425 (1986); (d) K. Ito, S. Yokoyama, F. Arakawa, Y. Yukawa, N. Iwashita, and Y. Yamasaki, Polym. Bull., 16, 337 (1986); (e) K. Ito, S. Yokoyama, and F. Arakawa, Polym. Bull., 16, 345 (1986); (f) K. Ito, F. Arakawa, H. Tanaka, K. Hashimura, and S. Itsuno, Asahi Glass Kogyo Gijutsu Syoreikai Kenkyu Hokoku, 54, 105 (1989).

8. K. Ito, K. Tanaka, H. Tanaka, G. Imai, S. Kawaguchi, and S. Itsuno, Macromolecules, 24, 2348 (1991).

9. K. Ito, K. Hashimura, and S. Itsuno, Macromolecules, in press.

10. P. G. McDougal, J. G. Rico, Y.-I. Oh, and B. D. Condon, J. Org. Chem., 51, 3388 (1986).

11. D. Braun and H. G. Keppler, Makromol. Chem., 94, 1250 (1964).

12. M. Tomoi, E. Ogawa, Y. Yokoyama, and H. Kakiuchi, J. Polym. Sci., Polym. Chem. Ed., 20, 3015 (1982).

13. K. Tanaka, Master's Thesis, Toyohashi University of Technology (Mar. 1988). 